\title{
CONCEPÇÕES SOBRE ESCOLA E GÊNERO NA PERSPECTIVA DE CRIANÇAS ABRIGADAS
}

\author{
Ana Cláudia Bortolozzi MAIA ${ }^{1}$ \\ Natália Pinheiro ORTI ${ }^{2}$ \\ Vivian Bonani de SOUZA ${ }^{3}$
}

RESUMO: A escola e a família são contextos fundamentais para a formação de conceitos na infância e poucos estudos são realizados a partir do relato de crianças quando essas vivem em casa-abrigo. O objetivo deste estudo foi investigar que concepções as crianças em situação de abrigamento apresentam sobre escola e gênero. Participaram 22 crianças, de ambos os sexos, entre 4 e 6 anos, que responderam a uma entrevista com questões abertas para a análise de conteúdo. Para essas crianças, a escola foi associada a um espaço de oportunidade de estudo, favorável a elas mesmas, ainda que por necessidade ou obrigação e, eventualmente, com a presença de conflitos. O gênero foi percebido a partir de aspectos biológicos e psicossociais e as crianças atribuem sua identidade de gênero ao destino, à aprendizagem e às vantagens sociais. As crianças sentem-se pertencentes a um gênero de modo positivo, embora para isso atribuam desvantagens ao gênero oposto, relacionando o sexo masculino à agressividade e à violência. As crianças reproduzem alguns padrões e características sociais de gênero que, provavelmente, foram aprendidas em diferentes contextos. Conclui-se que estudos nessa área são importantes para desvelar as concepções na infância sobre a escola e a sexualidade, suas funções e representações, especialmente quando as crianças vivem em um contexto com características bem específicas como o abrigamento.

PALAVRAS-CHAVE: Escola. Gênero. Infância. Abrigo.

\section{Introdução}

A escola é, juntamente com a família, um contexto importante para desenvolvimento humano (DESSEN; POLONIA, 2007; PEREZ, 2010); possui funções sociais, políticas e educacionais, na medida em que é responsável pela transmissão e construção do conhecimento culturalmente organizado. O currículo formal assegura a instrução e apreensão de conhecimentos culturalmente organizados por meio de atividades sistemáticas, o que potencialmente possibilita a apropriação da experiência acumulada socialmente através da linguagem simbólica (DESSEN; POLONIA, 2007). Além disso, a escola desempenha importante papel no desenvolvimento das funções

${ }^{1}$ UNESP - Universidade Estadual Paulista. Bauru - SP - Brasil. 17033-360 - aclaudia@ @c.unesp.br

${ }^{2}$ Mestranda em Psicologia do Desenvolvimento e da Aprendizagem. UNESP - Universidade Estadual Paulista. Bauru - SP - Brasil. 17033-360 - natiorti@ yahoo.com.br

${ }^{3}$ Mestranda em Psicologia do Desenvolvimento e da Aprendizagem. UNESP - Universidade Estadual Paulista. Bauru - SP - Brasil. 17033-360 - vivinha_souza@yahoo.com.br 
psicológicas e pode ser considerada uma importante fonte de apoio e estabelecimento de vínculos afetivos (SIQUEIRA, 2009); portanto constitui-se como um contexto fundamental para desencadear e fomentar a formação de conceitos e os diferentes processos de desenvolvimento humano (DESSEN; POLONIA, 2007).

Dentre os aspectos do desenvolvimento humano está a sexualidade, definida por Maia e Maia (2005) como um conceito amplo e abrangente que agrega relações de afeto, sentimentos, genitalidade, concepções e relações de gênero. Sobre o último aspecto citado, diversos autores atestam sobre a construção de gênero depender de processos educativos (BELLOTI, 1975; AFONSO, 1995; WHITAKER, 1995; MAIA; MAIA, 2009; REIS; MAIA, 2010). De acordo com Felipe (1998), para a perspectiva das relações de gênero importa discutir os processos de construção histórica, lingüística e social, instituídas na formação meninas e meninos; nesse sentido gênero constitui-se como uma categoria relacional e contextual que busca contemplar as complexidades e conflitos existentes na formação dos sujeitos.

A aprendizagem acerca das questões de gênero inicia-se desde a primeira infância, a partir das expectativas e experiências que meninas e meninos encontram desde o nascimento (PAPALIA et al., 2006; FIGUEIRÓ, 2006; MAIA, 2001; WHITAKER, 1995). Maia e Maia (2005) destacam que as diferentes concepções de sexualidade dos adultos constroem diferentes formas de perceber e influenciar a vivência da sexualidade na infância e posteriormente. Nesse sentido, a identidade de gênero é construída e transformada continuamente durante a vida, portanto refere-se à identificação histórica e social dos sujeitos que se reconhecem como femininos ou masculinos através das múltiplas relações com a cultura, isto é, a formação dos meninos e meninas ocorre no convívio entre eles, considerando também outras categorias, por exemplo, a classe social, a religião, a etnia (FELIPE, 1998; LOURO, 1997).

Os pais exercem grande influência sobre as crianças, para que elas desempenhem comportamentos desejados em relação ao gênero definido como uma construção sócio-cultural. Na mesma direção, a escola emprega diversos interlocutores e recursos para controlar, vigiar e normatizar a sexualidade infantil, na tentativa de moldarem os comportamentos que consideram mais apropriados para meninos e meninas (FELIPE, 1998; LOURO, 1997). As crianças são direcionadas a se identificar com modelos sexuais e começam a se comportar de acordo com a transmissão cultural sobre gênero masculino e feminino (AFONSO, 1995), o que leva a interpretação, avaliação e 
internalização de padrões socialmente transmitidos em relação ao gênero (ALENCAR, 1982; AFONSO, 1995; COLE; COLE, 2003).

Nesse sentido, a presente pesquisa teve como objetivo investigar que concepções as crianças em situação de abrigamento apresentam sobre escola e gênero. Mas especificamente, dar voz às crianças para conhecer a respeito do que pensam e como entendem o fato de freqüentarem a escola, assim como de que forma percebem as diferenças de gênero e como se identificam.

\section{Método}

Esta pesquisa é qualitativa-descritiva (CAMPOS, 2000; SPATA, 2005) e respeitou todos os procedimentos éticos em pesquisas com seres humanos, isto é, ela só foi realizada após parecer favorável do Comitê de Ética, da instituição abrigo envolvida consentir e autorizar a pesquisa, além de seus dirigentes responsabilizarem-se pela participação das crianças.

Os participantes foram 22 crianças abrigadas com idade entre 4 e 11 anos, sendo 11 meninas e 11 meninos. Foram adotados três critérios de inclusão, no qual a criança deveria compreender a linguagem e saber manter interação verbal; ter interesse em participar e ter tido a autorização dos responsáveis da instituição. A ampla diferença de idade entre os participantes da presente pesquisa justifica-se porque se tratavam de todas as crianças abrigadas na instituição no momento da investigação. Nesse sentido, o que caracterizou o grupo de participantes foi a situação de abrigamento comum às crianças e não especificamente a idade cronológica de cada uma delas.

Para a coleta de dados utilizou-se de um roteiro de questões aperfeiçoado após aplicação piloto com crianças similares aos participantes. Tal roteiro de entrevista continha os seguintes temas de investigação: conceitos sobre escola e concepções de gênero. As perguntas feitas às crianças foram divididas em dois blocos. No bloco de questões sobre escola, as perguntas foram: 1) "Por que você acha que uma criança tem que ir para a escola?"; 2) "Você gosta de ir à escola? Por que?". No bloco de questões sobre gênero, as questões foram: 3) "O que meninos e meninas têm diferente?"; 4) "Você é menino ou menina? Por que?"; 5) "É melhor ser menino ou menina? Por que?". As entrevistas ocorreram em uma sala reservada na própria instituição, com privacidade e condições adequadas para que as crianças se sentissem confortáveis na interação verbal. As entrevistas não foram gravadas para não inibir as crianças, mas todas as respostas 
foram anotadas na íntegra pelas pesquisadoras. Para análise de dados foi utilizado procedimento de análise de conteúdo temático (BARDIN, 1979) muito utilizado em pesquisas qualitativas (SPATA, 2005). Cada criança foi identificada pela letra maiúscula C seguindo do número ordinal de 1 a 22.

\section{Resultados}

\section{Concepção de escola}

As respostas das crianças sobre a concepção de escola foram agrupadas em dois conjuntos temáticos: (1.1) Motivos pelos quais crianças vão à escola e (1.2) Preferência por freqüentar a escola e justificativas.

Com relação à questão sobre porque crianças devem ir à escola, 8 crianças relatam que devem ir à escola porque nela encontram o saber, o aprendizado da leitura e escrita. Por outro lado, 6 crianças apresentam que é preciso ir, como uma "obrigação". Outras 3 crianças relatam motivos de que pela escola é possível pensar em melhores condições de vida. Enquanto duas crianças justificam a ida à escola porque gostam da professora, outras duas crianças responderam que devem ir à escola porque é bom. Apenas uma delas não respondeu a essa questão. A Tabela 1 mostra os agrupamentos em categorias das respostas das crianças sobre porque devem ir à escola.

Tabela 1 - Categorias de respostas relacionadas aos motivos para freqüentar a escola.

\begin{tabular}{l|l|l}
\hline Categorias & Crianças & Exemplos de relatos \\
\hline $\begin{array}{l}\text { Oportunidade de estudar e } \\
\text { aprender }\end{array}$ & $\begin{array}{l}\mathrm{C} 4, \mathrm{C} 5, \mathrm{C} 6, \mathrm{C} 8, \mathrm{C} 12, \\
\mathrm{C} 15, \mathrm{C} 17, \mathrm{C} 18\end{array}$ & $\begin{array}{l}\text { "Pra aprender ler e escrever"; "Pra } \\
\text { aprender"; "Porque tem que estudar, } \\
\text { aprender e ler". }\end{array}$ \\
\hline $\begin{array}{l}\text { Acesso a faculdade, } \\
\text { profissão e outras } \\
\text { condições de vida }\end{array}$ & $\mathrm{C} 1, \mathrm{C} 2, \mathrm{C} 3$ & $\begin{array}{l}\text { "Pra não ficar burra, pra ter vida boa } \\
\text { depois"; "pra quando crescer ter trabalho, } \\
\text { casa e ter dinheiro e sustentar a casa" }\end{array}$ \\
\hline $\begin{array}{l}\text { Dever e obrigação de } \\
\text { estudar }\end{array}$ & $\begin{array}{l}\mathrm{C} 10, \mathrm{C} 13, \mathrm{C} 14, \mathrm{C} 16, \\
\mathrm{C} 19, \mathrm{C} 21\end{array}$ & $\begin{array}{l}\text { "Porque vai todo mundo..não tem férias"; } \\
\text { "Porque é pra ir". }\end{array}$ \\
\hline $\begin{array}{l}\text { Vinculo positivo com a } \\
\text { professora }\end{array}$ & $\mathrm{C} 9, \mathrm{C} 11$ & "Porque lá a gente gosta da professora" \\
\hline Prazer, satisfação & $\mathrm{C} 20, \mathrm{C} 22$ & "Porque a gente gosta" \\
\hline Não respondeu & $\mathrm{C} 7$ & Não respondeu. \\
\hline
\end{tabular}

Fonte: Elaboração própria. 
Quando perguntadas se gostam de ir à escola e por que, oito crianças consideraram a escola um lugar ruim. Dentre elas, duas crianças justificaram que não gostam de ir à escola porque o lugar é desprazeroso e 6 crianças relacionaram o desprazer às tarefas e relacionamentos ruins. Algumas crianças relataram que a escola é "chata" e nela há situações de violência ("eles xingam", "me batem lá", "batem na bunda"). A maior parte das crianças (14) consideram a escola um lugar para o qual gostam de ir, seja porque nela podem aprender, como estudar e ter uma profissão, seja porque nela há vínculos afetivos (“amizades", "professora”). A Tabela 2 mostra esses dados.

Tabela 2 - Categorias de respostas relacionadas à preferência por ir à escola e
justificativas.

\begin{tabular}{|c|c|c|c|}
\hline Categorias & Sub categorias & Crianças & Exemplos de relatos \\
\hline \multirow{4}{*}{$\begin{array}{l}\text { Lugar Bom } \\
\text { (Gosto de ir) }\end{array}$} & $\begin{array}{ll}\begin{array}{l}\text { Situação } \\
\text { aprendizagem }\end{array} & \text { de }\end{array}$ & C6, C18 & $\begin{array}{l}\text { "Gosto, é bom aprender"; "Gosto porque } \\
\text { tem atividade, e quem aprende não fica } \\
\text { burro" }\end{array}$ \\
\hline & $\begin{array}{l}\text { Vínculos afetivos } \\
\text { favoráveis }\end{array}$ & $\begin{array}{l}\text { C4, C10, } \\
\text { C13, C19 }\end{array}$ & $\begin{array}{l}\text { "Todas as escolas que fui eu gostei, } \\
\text { porque faço amizades"; "Gosto, porque } \\
\text { sim, a professora é legal" }\end{array}$ \\
\hline & $\begin{array}{l}\text { Diversão e } \\
\text { alimentação }\end{array}$ & $\begin{array}{l}\text { C5, C12, } \\
\text { C14, C16, } \\
\text { C20, C21 }\end{array}$ & $\begin{array}{l}\text { "Sim, tem comida"; "Sim, porque } \\
\text { brinco"; "Gosto, porque tem carne, ovo, } \\
\text { berinjela e pão" }\end{array}$ \\
\hline & $\begin{array}{l}\text { Melhores condições } \\
\text { de vida, ter } \\
\text { profissão }\end{array}$ & $\mathrm{C} 1, \mathrm{C} 2$ & "Sim, porque vou ter um bom trabalho" \\
\hline \multirow[t]{2}{*}{$\begin{array}{l}\text { Lugar Ruim } \\
\text { (Não gosto de ir) }\end{array}$} & Lugar desprazeroso & $\mathrm{C} 7, \mathrm{C} 8$ & $\begin{array}{l}\text { "Não gosto. (Quando estou lá) quero ir } \\
\text { dormir na casa do meu pai" }\end{array}$ \\
\hline & $\begin{array}{l}\text { Tarefas, } \\
\text { relacionamentos } \\
\text { ruins }\end{array}$ & $\begin{array}{l}\text { C3, C9, } \\
\text { C11, C15, } \\
\text { C17, } \mathrm{C} 22\end{array}$ & $\begin{array}{l}\text { "Não, é chato escrever, e a professora é } \\
\text { chata"; "Não porque lá me batem na } \\
\text { bunda"; "Não, não gosto, me batem lá" }\end{array}$ \\
\hline
\end{tabular}

Fonte: Elaboração própria.

\section{Concepção de gênero}

As respostas das crianças sobre gênero foram agrupadas em três conjuntos temáticos: (2.1) Percepção das diferenças sexuais; (2.2) Identidade de gênero e justificativas; (2.3) Preferência e percepção sobre o próprio gênero.

Com relação à compreensão de crianças sobre a percepção das diferenças sexuais, foram encontradas 3 categorias de respostas. Para 9 crianças as diferenças entre meninos e meninas se referiram aos aspectos comportamentais e sociais, categoria identificada a partir de exemplos de atitudes, brincadeiras e vestimentas. Para 8 crianças, as diferenças entre meninos e meninas foram relacionadas às diferenças corporais e 
físicas, em referência direta ou indireta às partes do corpo não-sexuais e sexuais. Cinco crianças não sabem/não explicaram as diferenças entre meninos e meninas. Os resultados sobre percepção das diferenças sexuais são apresentados na Tabela 3.

Tabela 3 - Categorias de respostas relacionadas à percepção das diferenças sexuais.

\begin{tabular}{l|l|l}
\hline Categorias & Crianças & Exemplos de relatos \\
\hline $\begin{array}{l}\text { Aspectos } \\
\text { comportamentais e } \\
\text { sociais }\end{array}$ & $\begin{array}{l}\mathrm{C} 1, \mathrm{C} 6, \mathrm{C} 7, \mathrm{C} 9, \mathrm{C} 11, \\
\mathrm{C} 17, \mathrm{C} 18, \mathrm{C} 19, \mathrm{C} 21\end{array}$ & $\begin{array}{l}\text { "Menina tem vestido e menino tem chapéu"; } \\
\text { "Menino tem carrinho e menina tem boneca"; } \\
\text { "Homens batem, mulheres não". }\end{array}$ \\
\hline Diferenças corporais & $\begin{array}{l}\mathrm{C} 2, \mathrm{C} 3, \mathrm{C} 4, \mathrm{C} 12, \mathrm{C} 14, \\
\mathrm{C} 16, \mathrm{C} 20, \mathrm{C} 22\end{array}$ & $\begin{array}{l}\text { "Homem tem cabelo curto e mulher tem cabelo } \\
\text { longo"; "Aquilo que tem no meio da perna: pipi } \\
\text { e periquita"; "Homens tem bigode e mulher não } \\
\text { tem". }\end{array}$ \\
\hline $\begin{array}{l}\text { Não sabem/não } \\
\text { explicaram }\end{array}$ & $\mathrm{C} 5, \mathrm{C} 8, \mathrm{C} 10, \mathrm{C} 13, \mathrm{C} 15$ & "Não sei" ou mudaram de assunto \\
\hline
\end{tabular}

Fonte: Elaboração própria.

Em relação à compreensão das crianças sobre a própria identidade de gênero e como a explicam, foram identificadas 4 categorias de respostas. Observou-se que 8 crianças justificaram ser menino/menina porque atribuem qualidades e vantagens ao gênero com o qual se identificam. Cinco crianças justificaram a identificação com o gênero por um destino natural e três crianças justificaram seu gênero com base na indicação social recebida. Uma criança respondeu sobre sua identidade de menino porque tem órgão sexual específico, enquanto cinco crianças não responderam ou não justificaram por que eram meninas ou meninos. Esses dados estão na Tabela 4.

Tabela 4 - Categorias de respostas relacionadas à identidade de gênero.

\begin{tabular}{l|l|l}
\hline Categorias & Crianças & Exemplos de relatos \\
\hline $\begin{array}{l}\text { Atribuem qualidades e } \\
\text { vantagens ao próprio } \\
\text { gênero }\end{array}$ & $\begin{array}{l}\mathrm{C} 1, \mathrm{C} 3, \mathrm{C} \text {, } 1, \mathrm{C} 12, \mathrm{C} 17, \\
\mathrm{C} 21, \mathrm{C} 22\end{array}$ & $\begin{array}{l}\text { "Menina dá menos trabalho e tem roupa bonita"; } \\
\text { "Não tenho que bater sendo menina, mas se bater } \\
\text { não sou covarde como meu padrasto"; "Menino é } \\
\text { mais amigo". }\end{array}$ \\
\hline Destino natural & $\begin{array}{l}\mathrm{C} 2, \mathrm{C} 4, \mathrm{C} 13, \\
\mathrm{C} 18, \mathrm{C} 20\end{array}$ & $\begin{array}{l}\text { "Sou menino porque nasci assim"; "Porque meu pai } \\
\text { falou para Deus dar menino" }\end{array}$ \\
\hline Indicação social & $\mathrm{C} 6, \mathrm{C} 7, \mathrm{C} 9$ & $\begin{array}{l}\text { "Tenho nome de mulher"; "Por que eu aprendi que } \\
\text { sou menino". }\end{array}$ \\
\hline Órgão sexual específico & $\mathrm{C} 14$ & "Sou menino porque tenho pipi" \\
\hline Não sabe/não respondeu & $\begin{array}{l}\mathrm{C} 8, \mathrm{C} 9, \mathrm{C} 10, \\
\mathrm{C} 15, \mathrm{C} 16\end{array}$ & "Não sei" ou mudaram de assunto \\
\hline
\end{tabular}

Fonte: Elaboração própria. 
Em relação à preferência e percepção sobre gênero 7 crianças $(\mathrm{C} 2, \mathrm{C} 4, \mathrm{C} 5, \mathrm{C} 7$. C10, C11 e C18) alegaram preferir o gênero com o qual se identificam justificando através de características negativas que atribuem ao outro gênero. Exemplos: "Prefiro ser menina porque menino é malandrão"; "Porque menino bate e menina não"; "Menino pode ter bom ou mau, mas meninas têm milhões de más e poucas boas". Por outro lado, 9 crianças (C3, C6, C9, C13, C15, C17, C20, C21 e C22) relataram preferência pelo gênero com o qual se identificam enquanto ressaltam características positivas que atribuem ao próprio gênero. Além disso, 6 crianças não responderam ou não identificaram a preferência por algum dos gêneros. Exemplos: "Menina sabe que não é para bater"; "Menino pode ter mais coisas, até celular" (grifos nosso).

\section{Discussão}

A maioria das crianças abrigadas percebeu a escola como um local positivo, onde encontram prazer e acolhimento, marcado pelos vínculos afetivos e pela expectativa de uma vida melhor. Ao analisar o momento inicial das crianças no percurso escolar, da passagem da educação e infantil para a fundamental, Teixeira (2008) constatou a tendência das crianças atribuírem à escola um valor positivo, como possibilidade de novos conhecimentos, sendo a escola associada ao seu papel social de transmissão de saber.

Entretanto, algumas crianças identificaram na escola um local de desprazer com tarefas chatas e ocorrências violência. Tais dados são concordantes com os achados de Buffa et al. (2010), que ao investigarem, pela perspectiva de crianças e técnicos de um abrigo, como a condição de abrigamento perpassa as vivências e relações dessas crianças no contexto escolar, observaram que as crianças pesquisadas descreveram suas interações escolares como problemáticas e freqüentemente violentas, indicando possivelmente conflitos significativos estar se repetindo no contexto escolar.

Autores descrevem que compreensão das crianças sobre sexualidade e gênero depende de aspectos afetivos, emocionais e cognitivos, portanto relacionados à história de vida e à educação sexual, fatores os quais variam conforme as condições históricoculturais de desenvolvimento de cada criança (JAGSTAID,1987; NUNES; SILVA, 2000). Nesse sentido, entende-se que as respostas das crianças representam significados construídos em contextos de desenvolvimento e educação sexual diversificados e desconhecidos dos pesquisadores, o que não permite generalizações e interpretações acerca de como tais conceitos de gênero foram estabelecidos. 
O adulto é compreendido como mediador fundamental para proporcionar as condições de compreensão infantil da sexualidade, uma vez que é na interação com o adulto que a criança reconhece modelos de comportamento, aprende significados de suas atitudes e inicia sua formação da identidade de gênero (MAIA; MAIA, 2005; AFONSO, 1995. No caso do gênero, as crianças perceberam as diferenças sexuais tanto pelos aspectos comportamentais e sociais, citando atitudes, brincadeiras e vestimentas e também às diferenças corporais e físicas, em referência direta ou indireta às partes do corpo não-sexuais e sexuais caracterizando, portanto, que a categoria gênero se evidenciou como uma construção cultural e histórica (FELIPE, 1998; LOURO, 1997).

Na infância é comum que as crianças identifiquem noções sexuais primeiro pelas diferenças corporais e depois pelas representações sociais (MAIA; MAIA, 2005; RIBEIRO, 1990; NUNES; SILVA, 2000). O fato das crianças diferenciarem os gêneros a partir da identificação de estereótipos onde as características são estáticas sugere a reprodução de uma visão binária e dicotômica de gênero (RABELLO; CALDEIRA, 2010), através da normalização do que se espera do comportamento de meninos e meninas (MORENO, 1999; MAIA; MAIA, 2005, 2009). Dentre os relatos sobre percepção das diferenças de gênero encontram-se aqueles que destacam as diferenças corporais; por vezes tais relatos também revelam estereótipos da corporeidade masculina e feminina predominante na cultura (como o comprimento e aspecto dos cabelos), mas predominantemente nessa categoria as crianças igualam gênero à presença de determinadas características sexuais primárias ou secundárias (pênis ou bigode), relevando uma naturalização da construção de gênero e redução a aspectos biológicos (AFONSO, 1995; NUNES; SILVA, 2000; WHITAKER, 1995).

Nos relatos sobre identidade de gênero, na categoria que releva concepções sobre um destino natural como determinante do gênero, as crianças reduzem a percepção de gênero ao acaso ou à divindade, não associando serem meninos ou meninas ao próprio corpo ou às transmissões culturais do processo de Educação Sexual. Por outro lado, quando destacam qualidades e vantagens sociais do gênero com o qual se identificam, as crianças mencionam características que supostamente são superiores e restritas ao gênero com o qual se identificam. Isso também ocorre em relação aos relatos sobre a preferência por pertencer ao gênero com o qual se identificam, quando parte das crianças destacam vantagens que supostamente seriam inacessíveis a pessoas do outro gênero. Em ambos os casos, sugere-se que as crianças que caracterizam um gênero como superior ou mais vantajoso que o outro, possivelmente, tiveram experiências nas quais a desigualdade de 
diretos e oportunidades entre os gêneros revelou-se como "natural" (BELOTTI, 1975; MORENO, 1999). Por outro lado, houve crianças que no processo de diferenciar o que percebem como vantagens de pertencer a um gênero destacaram as desvantagens atribuídas ao gênero oposto. Mais uma vez, se referiram a estereótipos sexuais amplamente difundidos e naturalizados, como agressividade relacionada aos meninos (REIS; MAIA, 2010; FERREIRA et al., 2003; BELOTTI, 1975), e isso provavelmente tem relação com o contexto que levou ao abrigamento, a história de vida marcada por negligencia e/ou violência, percebida pelas crianças como predominante nos comportamentos adultos masculinos.

\section{Considerações Finais}

A concepção sobre escola foi associada a um espaço de oportunidade de estudo, favorável a elas mesmas, ainda que por necessidade ou obrigação e, eventualmente, com a presença de conflitos adicionais. Além disso, é interessante destacar que para algumas dessas crianças a escola é um lugar bom porque nela há brincadeiras e comida.

O gênero, por sua vez, foi percebido por este grupo de crianças pelos aspectos biológicos e psicossociais, enquanto atribuíram sua identidade de gênero ao destino, à aprendizagem e às vantagens sociais. As crianças sentem-se pertencentes a um gênero de modo positivo, embora para isso frequentemente atribuam desvantagens ao gênero oposto. Além disso, houve reprodução de alguns padrões e características sociais de gênero, que provavelmente foram aprendidas em diferentes contextos de mediação social, reforçando a ideia de que o gênero é uma construção cultural.

Nesse sentido, entende-se que estudos nessa área tornam-se importantes para desvelar a influência dos aspectos culturais na construção de gênero e sobre as concepções de escola na infância - sua função e representação a partir de diferentes idades, especialmente em um contexto com características bem específicas como o abrigamento.

\section{SCHOOL AND GENDER CONCEPTS FROM THE PERSPECTIVE OF CHILDREN IN REST-HOME}

ABSTRACT: School and family are critical contexts to the development of concepts in childhood and few studies are conducted from the report of children when they live in rest-home. The aim of this study was to investigate concepts that children in rest-homes 
have about school and gender. There were 22 participants, including boys and girls, between 4 and 6 years, who were interviewed with open questions for content analysis. For these children the school was associated with an area of study opportunities, favorable to themselves, although by necessity or obligation, and possibly with the presence of conflicts. The gender was described from biological and psychosocial aspects and children attributed their gender identity at destination, learning and social advantages. Children feel they belong to a gender in a positive way, although by attributing disadvantages to the opposite gender, for example, relating male aggression to violence. Children reproduce some patterns and social characteristics of gender that probably were learned in different contexts. We conclude that studies in this area are important to identify children's conceptions about school and sexuality, their roles and representations, especially when they live in an environment with such specific features as a rest-home.

KEYWORDS: School. Gender. Childhood. Rest-home.

\section{REFERÊNCIAS}

AFONSO, L. Gênero e processo de socialização em creches comunitárias. Cadernos de Pesquisa, São Paulo, v. 93, p.12-21, mai. 1995.

ALENCAR, E. M. L. S. A criança na família e na sociedade. Petrópolis: Vozes, 1982.

BARDIN, L. Análise de conteúdo. Lisboa: 70, 1979.

BELOTTI, E. G. Educar para a submissão: o descondicionamento da mulher. Petrópolis: Vozes, 1975.

BUFFA, C. G. et al. Vivências de exclusão em crianças abrigadas. Psicologia: teoria e prática, v.12, n.2, p.17-34, 2010. Disponível em:

<http://redalyc.uaemex.mx/redalyc/pdf/1938/193817420003.pdf>. Acesso em: 16 jun. 2011.

CAMPOS, L. F. L. Métodos e técnicas de pesquisa em psicologia. Campinas: Alínea, 2000.

COLE, M.; COLE, S. R. O desenvolvimento da criança e do adolescente. 4. ed. Porto Alegre: ARTMED, 2003.

DESSEN, M. A.; POLONIA, A. C. A família e a escola como contextos de desenvolvimento humano. Paidéia, Ribeirão Preto, v.17, n.36, p.21-32, 2007. Disponível em: <http://www.scielo.br/pdf/paideia/v17n36/v17n36a03.pdf >. Acesso em: 03 jun. 2011.

FELIPE, J. Sexualidade nos livros infantis: relações de gênero e outras implicações. In: MEYER, D. (Org.). Saúde e sexualidade na escola. Porto Alegre: Mediação, 1998. p.111-124.

FERREIRA, A. P. et al. Refletindo sobre a sexualidade na educação infantil. Revista Linhas, Florianópolis, v.4, n.1, 2003. Disponível em: 
<http://www.periodicos.udesc.br/index.php/linhas/article/view/1205>. Acesso em: 16 jun. 2011.

FIGUEIRÓ, M. N. D. Formação de educadores sexuais: adiar não é mais possível. Londrina: Ed. da UEL, 2006.

JAGSTAID, V. A sexualidade e a criança. São Paulo: Manole, 1987.

LOURO, G. Gênero, sexualidade e educação. Petrópolis: Vozes, 1997.

511 MAIA, A. C. B. Reflexões sobre a educação sexual da pessoa com deficiência. Revista Brasileira de Educação Especial, Marília, v.7, n.1, p.35-46, 2001.

MAIA, A. C. B.; MAIA, A. F. (Org.) Sexualidade e infância. Bauru: Faculdade de Ciências; Brasília: MEC/SEF, 2005. (Cadernos CECEMCA, n.1).

. Educação para as questões de gênero e diversidade sexual. In: MORAES, M. S. S.; MARANHE, E. A. (Org.). Educação na diversidade e cidadania. Bauru: Faculdade de Ciências; Brasília: MEC/SEF, 2009. p.46-64. (Cadernos CECEMCA, n.1).

MORENO, M. Como se ensina a ser menina: o sexismo na escola. Tradução Ana Venite Fuzatto. São Paulo: Moderna, 1999.

NUNES, C. A.; SILVA, E. A educação sexual da criança. Campinas: Autores Associados, 2000. (Coleção Polêmicas do nosso tempo).

PAPAPLIA, D. E; OLDS, S. W.; FELDMAN, R. D. Desenvolvimento Humano. 8. ed. Porto Alegre: ARTMED, 2006.

PEREZ, M. A. C. Família e escola na contemporaneidade: fenômeno social. Revista Ibero-Americana de Estudos em Educação, Araraquara, v. 4, n.3, 2010. Disponível em: 〈http://seer.fclar.unesp.br/iberoamericana/article/view/2763>. Acesso em: 24 jun. 2011.

RABELLO, S. H. S.; CALDEIRA, A. M. A. Gênero, pedagogias culturais e educação sexual: A questão da diferença entre meninos e meninas. In: CONGRESSO INTERNACIONAL SEXUALIDADE E EDUCAÇÃO SEXUAL, 2010, Aveiro. Anais... Disponível em:

$<$ http://issuu.com/ndsim/docs/cises?mode=embed\&layout=http://skin.issuu.com/v/light/la yout.xml\&showFlipBtn=true\&pageNumber=2>. Acesso em: 24 jun. 2011.

REIS, K. C. F.; MAIA, A. C. B. Educação e construção de gênero: características e vantagens do masculino e feminino na concepção de mulheres. Doxa: Revista Paulista de Psicologia e Educação, Araraquara, v.14, p.1, 2010.

RIBEIRO, P. R. Educação Sexual: além da informação. São Paulo: EPU, 1990.

SIQUEIRA, A. C. Escola como parte da rede de apoio de adolescentes em reinserção familiar. VIDYA, Santa Maria, v.29, n.2, p.87-96. 2009. Disponível em: 
<http://sites.unifra.br/Portals/35/Artigos/2009/vol_2/escola.pdf >. Acesso em: 23 jun. 2011.

SPATA, A. Métodos de pesquisa: ciência do comportamento e diversidade humana. Rio de Janeiro: LTC, 2005.

TEIXEIRA, T. C. F. Da educação infantil ao ensino fundamental: com a palavra, a criança. Um estudo sobre a perspectiva infantil no início do percurso escolar. 2008. 157f. Dissertação (Mestrado em Educação) - Universidade de São Paulo, São Paulo, 2008.

WHITAKER, D. C. A. Menino - Menina: sexo ou gênero? In: SERBINO, R. V.;

GRANDE, M. A. R. L. (Org.). A escola e seus alunos: o problema da diversidade cultural. São Paulo: Ed. da UNESP, 1995. p.31-52. 